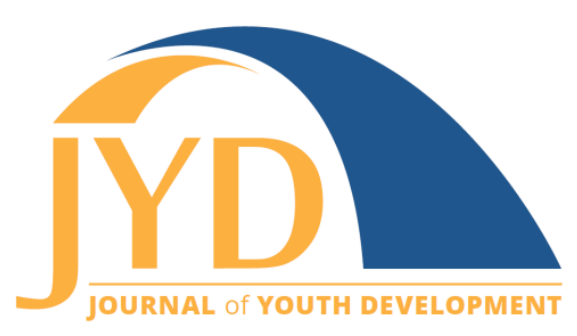

http://jyd.pitt.edu/ | Vol. 15 Issue 4 DOI 10.5195/jyd.2020.984 | ISSN 2325-4017 (online)

\title{
Volunteerism in Youth Development Programs: Editors' Note
}

\author{
JoLynn C. Miller \\ University of California Agriculture and Natural Resources \\ jlmiller@ucanr.edu
}

Kali Trzesniewski

University of California, Davis

ktrz@ucdavis.edu

\begin{abstract}
Youth development programs are varied and diverse. Some rely on paid staff to deliver programming, but many rely on volunteers. While there is quite a bit of research on volunteers and volunteerism in general, there is little that goes in depth covering the nuances of volunteers in youth development organizations. The editors of this special issue introduce the articles, which cover themes of understanding the impacts of volunteers, volunteer competencies and skill development, support and motivation of volunteers, and evaluation of programs. In addition, a book review and a closing reflection are included. Finally, the editors close with their thoughts about exciting directions for the future of volunteer development research and practice.
\end{abstract}

Key words: volunteerism, volunteering, youth development, youth programs

Many youth-serving organizations rely on volunteers for the delivery of their program. In fact, for some organizations, volunteers are the only way program is delivered. Although there has been a fair amount of research on volunteering, there are gaps in the literature. For example, Wilson (2012) highlights a gap in understanding the volunteer experience, compared to understanding the antecedents and consequences of volunteering. Moreover, the literature base is more limited for volunteer development for youth-serving organizations. Recent work has highlighted the important role of context and relationship-building in developing positive outcomes for youth (Arnold, 2018). As such, it is important not only to understand how to 
recruit and retain volunteers for youth-serving organizations, but also how to raise their capacity to provide high-quality contexts and programming to help youth thrive. That is, theories of positive youth development emphasize that adult leaders play a critical role in fostering thriving outcomes for youth. It is important to note that the needs of volunteers differ from those of the paid workforce (see Journal of Youth Development Special Issue on the Youth Development Workforce). These differences impact the ways organizations may approach recruitment and retention of volunteers, and professional development needs of volunteers, many of whom do not have youth development expertise. The goal of this special issue is to provide an overview of current knowledge on impacts of volunteering, professional development needs, volunteer competencies, and support for and motivations of volunteers. We hope that the results of these research studies will help youth-serving organizations strengthen their volunteer workforce and, as a result, improve youth outcomes. We also hope that it will stimulate new research to fill gaps in literature.

Understanding the impacts of being a volunteer can help organizations with recruitment of volunteers and potentially boost recruitment through increasing opportunities for volunteers to experience desired benefits. Worker et al. (2020) and Grant et al. (2020) found that 4-H volunteers most commonly reported their contributions were influencing, changing, or improving the program, culture, or young people directly. In addition, volunteers reported receiving benefits, such as developing skills (both for working with youth and transferable skills) and improved well-being. These results suggest that youth-serving organizations could focus on helping volunteers feel empowered to create change and provide opportunities for them to develop their skills. In addition, these concepts are a key gateway to begin further research exploring which specific volunteer characteristics or trainings may have an impact on youth outcomes.

The next five articles highlight gaps in volunteer competencies and skill development and provide suggestions on volunteer training. Kok et al. (2020) found that volunteers want training to increase their content knowledge and positive youth development skills, along with more organizational/management training. They also report modalities volunteers prefer for professional development. Homan et al. (2020) also report that volunteers want training focused around organization, program management, positive youth development, and communication. Hensley et al. (2020) conclude that training should focus on positive youth development and the role it plays in promoting youth outcomes, while also being thoughtful about frequency, modality, and opportunities outside of face-to-face training. Franck and 


\section{Volunteerism in Youth Development Programs}

Donaldson (2020) highlight the additional needs for skill development-specifically for STEM programs-given the difficulty of finding volunteers who have existing STEM and youth development experience. Using the 4-H Volunteer Research and Knowledge Competency as a baseline, White et al. (2020) suggest focusing training on volunteer teams; engaged youth and families; facilitation skills in experiential education and positive youth development; and effective program administration, communication, and information systems.

Several articles consider what motivates volunteers and what supports they need in their roles. Keller et al. (2020) and Restler and Glant (2020) discuss time and effort of support staff as being a key to supporting volunteers in their roles. Miranda-Díaz et al. (2020) confirmed an empathy-altruism hypothesis that suggests there is a connection between ethnocultural empathy and altruistic motivation for volunteering.

Morris and Ashby (2020), remind us of the importance of evaluating our organizations to ensure consistent and cohesive volunteer system. Their process of involving volunteers in revising the volunteer structure gives insight into how to successfully navigate change within a volunteer program.

In the penultimate article, a review of The 5 Languages of Appreciation in the Workplace, Morris (2020) explains how that book can be used in the context of volunteers in youth-serving organizations. She gives suggestions and tips on how organizations can use the information in the book as a tool to recognize and motivate their volunteer workforce.

Finally, based on his knowledge and experience as a mentoring and youth development expert, DuBois (2020) summarizes what we learn from the body of work presented in the special issue and outlines a research agenda that can help move the field of volunteer development forward.

In closing, we are proud of the issue presented and feel the authors have added significant literature to the field. The papers covered much ground and gave specific recommendations on where to move our research. A common thread among all is the acknowledgment of the importance of volunteers in our field. Without them, many programs would not exist. We must keep working to improve volunteers' experience, so the overall field of youth development continues to grow. One thing to consider when reading through these articles is where there are still gaps. While our call for papers included emphasis on how volunteers' backgrounds, training, and development could ultimately affect youth outcomes, none of the papers 
submitted addressed this topic specifically. This is not to say the articles found here are lacking - in fact, they are assets that increase the body of knowledge around the subject. Given the limited financial and personnel resources available to most youth-serving organizations, it is important that we invest our time in efforts that simultaneously enhance both volunteer experiences and positive youth development outcomes. Therefore, as professionals we must ensure that our research not only focuses on the volunteer experiences, but also seeks to understand the links among volunteer experiences, competencies, and professional development with the ultimate goal of positive youth outcomes.

\section{References}

Arnold, M. E. (2018). From context to outcomes: A thriving model for 4-H youth development programs. Journal of Human Sciences and Extension, 6(1). https://www.jhseonline.com/article/view/653

DuBois, D. (2020). Supporting volunteerism in youth development programs: Progress and prospects for advancing the knowledge base. Journal of Youth Development, 15(4), 206-216. https://doi.org/10.5195/jyd.2020.986

Franck, K. L., \& Donaldson, J. L. (2020). Volunteer training needs for successful 4-H STEM programs. Journal of Youth Development, 15(4), 97-109. https://doi.org/10.5195/jyd.2020.856

Grant, S., Maass, S., Vettern, R., Harrington, R., O'Neil, K., McGlaughlin, P., \& Good, T. (2020). The impact of volunteering: A multi-state study of $4-\mathrm{H}$ youth development volunteers. Journal of Youth Development, 15(4), 32-50. https://doi.org/10.5195/jyd.2020.870

Hensley, S. T., Kent, H. C., Broaddus, B. A., Ellison, S., Michael, S. T., \& Spero, V. (2020). 4-H volunteer attainment of quality positive youth development practices. Journal of Youth Development, 15(4), 87-96. https://doi.org/10.5195/jyd.2020.882

Homan, D., Epley, H. K., \& Bloir, K. L. (2020). Are volunteers competent in positive youth development? Perceptions from three stakeholder groups. Journal of Youth Development, 15(4), 68-86. https://doi.org/10.5195/jyd.2020.742

Keller, T. E., Drew, A. L., Clark-Shim, H., Spencer, R., \& Herrera, C. (2020). It's about time: Staff support contacts and mentor volunteer experiences. Journal of Youth Development, 15(4), 145-161. https://doi.org/10.5195/jyd.2020.879

Kok, C. M., Espinoza, D. M., Worker, S. M., Go, C., \& Miller, J. C. (2020). Identification of priority skill areas for volunteer professional development. Journal of Youth Development, 15(4), 51-67. https://doi.org/10.5195/jyd.2020.876 
Journal of Youth Development | http://jyd.pitt.edu/ | Vol. 15 Issue 4 DOI 10.5195/jyd.2020.984 Volunteerism in Youth Development Programs

Miranda-Díaz, M., Clark-Shim, H., Keller, T. E., \& Spencer, R. (2020). Determinants of motivation for mentoring among adults volunteering to mentor youth. Journal of Youth Development, 15(4), 174-189. https://doi.org/10.5195/jyd.2020.881

Morris, J. (2020). Book review: The 5 languages of appreciation in the workplace. Journal of Youth Development, 15(4), 202-205. https://doi.org/10.5195/jyd.2020.854

Morris, J., \& Ashby, L. (2020). Evaluating a statewide 4-H volunteer structure for protection and ease. Journal of Youth Development, 15(4), 190-201. https://doi.org/10.5195/jyd.2020.857

Restler, S., \& Glant, L. (2020). All hands on deck: Building a sustainable volunteer program. Journal of Youth Development, 15(4), 162-173. https://doi.org/10.5195/jyd.2020.877

White, A. J., Sero, R., Scanga, L. H., Cummins, M. M., Lile, J. R., Stott, N. K., \& Leach, J. (2020). "The right tools at the right time": Improving volunteer education and support. Journal of Youth Development, 15(4), 110-144. https://doi.org/10.5195/jyd.2020.878

Wilson, J. (2012). Volunteerism research: A review essay. Nonprofit and Voluntary Sector Quarterly, 41(2), 176-212. https://doi.org/10.1177/0899764011434558

Worker, S. M., Espinoza, D. M., Kok, C. M., Go, C., \& Miller, J. C. (2020). Volunteer outcomes and impact: The contributions and consequences of volunteering in 4- $\mathrm{H}$. Journal of Youth Development, 15(4), 6-31. https://doi.org/10.5195/jyd.2020.847 